\section{Omalizumab: NICE to USE you, to LOSE you NICE}

\author{
Andy Bush, ${ }^{1}$ Ian D Pavord ${ }^{2}$
}

National Institute for Health and Clinical Excellence (NICE) has just published draft recommendations for the use of omalizumab. These are as follows:

1. Omalizumab is not recommended within its marketing authorisation for treating severe persistent allergic asthma

2. People currently taking omalizumab should be able to continue treatment until they and their clinician consider it appropriate to stop. For children and adolescents, this decision should be made jointly by the clinician, the child or adolescent, and their parents or carers.

Clearly this blanket recommendation does not merely touch the confines of lunacy, but goes well beyond. Those who try to plough through NICE's obfuscatory documents would empathise with God's question to Job: Who is this that darkens counsel by words without knowledge?

\footnotetext{
${ }^{1}$ Imperial College \& Royal Brompton \& Harefield NHS Foundation Trust, London, UK; ${ }^{2}$ Department of Respiratory Medicine, Allergy and Thoracic Surgery, Institute for Lung Health, Glenfield Hospital, University Hospitals of Leicester NHS Trust, Leicester, UK
}

Correspondence to Professor Andy Bush, Department of Paediatric Respiratory Medicine, Imperial College \& Royal Brompton \& Harefield NHS Q6 Foundation Trust, London, UK; A.Bush@rbht.nhs.uk
However, it is facile solely to blame NICE for these ridiculous proposals; guilt must also be shared by doctors and the industry. The purpose of this annotation is not just to indulge in mere vulgar abuse of NICE, agreeable though this pastime may be, but to try at the 59th minute of the 11th hour to propose a way of salvaging something from the impending wreck. We propose a way forward which, since it will not please everyone, will in the best traditions of family life, annoy everyone hopefully equally.

It is common ground that (a) most patients with asthma can have their disease controlled with properly administered low to moderate doses of inhaled corticosteroids, sometimes supplemented by an additional controller such as long-acting $\beta-2$ agonists; (b) at least half of those referred to specialists with so-called therapy resistant asthma in fact need to get the basics right ${ }^{1-3}$ rather than indulge in expensive biologicals; and (c) omalizumab is hugely expensive and inconvenient to the patient. So how many specialists who are prescribing omalizumab can demonstrate that at least half of those considered for this therapy are turned down for non-adherence, failure to take reasonable measures to reduce environmental allergen exposure, failure to eliminate tobacco exposure and other such reasons ${ }^{4}$ ? Although clinicians in the UK might be less guilty of overuse of omalizumab than others, ${ }^{5}$ we are still not convinced that the therapy is being targeted effectively. Indeed, the old NICE guidelines for use of omalizumab arguably increased the possibility that therapy would be given inappropriately as they required a history of recurrent attacks leading to hospitalisation, episodes that are strongly associated with poor selfmanagement skills and non-adherence. ${ }^{6}$ Elsewhere mandatory protocols for assessment for omalizumab have been proposed $^{7}$; exactly zero progress has been made in making these compulsory. Similarly for assessment of benefit; zero progress in agreeing what actually needs to be measured and what constitutes a favourable response.

The industry is also culpable; of course they have an obvious and inevitable conflict of interest, having invested millions in developing a new medication, they want to maximise its use, both for financial reward and likely also because of a very genuinely held belief in efficacy. But this will simply not do when we are talking hugely expensive biologicals; perhaps somewhere deep in the small print you may find warnings about the need to use omalizumab very selectively, but we defy anyone to draw this lesson from the colourful advertisements and huge bold typefaces. Who regulates these matters, and what can they have been thinking of?

So the combination of industrial cupidity and professional laissez-faire has undoubtedly led to inefficient use of omalizumab, the waste of public money, and the new NICE proposals to throw out not merely the baby and the bathwater, but to smash the bath with an axe, and then blow up the bathroom 
and torch the whole house. The present practices must clearly cease; but can we do better?

In terms of treatment for patients who genuinely have therapy resistant asthma despite high levels of inhaled treatment, it has to be acknowledged that omalizumab is a much more appetising prospect than prednisolone, methotrexate and cyclosporine. Many clinicians who have used omalizumab will have stories of patients whose lives have been transformed by this treatment. What hope can we offer potential candidates for treatment if NICE's proposals go through? First, we must do all we can to be sure the therapy is being given to a responsive population. We should look again at the manufacturer's criteria for use of the therapy. Is there any evidence that the IgE level is related to efficacy of therapy? There is increasing evidence that it is not ${ }^{8}$ and that other biomarkers such as exhaled nitric oxide and blood eosinophils are better. ${ }^{9}$ Although it might be too much to have expected good predictive biomarkers at the time of the drug's launch surely we should have them now, after over a billion dollars of sales. It does the manufacturers no credit that they have repeatedly refused to allow their clinical dataset to be interrogated to identify better biomarkers of response; and it is not just in this context that Pharma are in trouble for being more secretive than the Mafia. They must rectify this urgently.

Second, patients must meet the criteria for problematic, severe asthma; any one of a number of proposals, all quite similar, are in the public domain ${ }^{310}$ and could be used. Omalizumab should only be prescribed by designated specialists, after a detailed and protocol driven evaluation of the patient. If the patient will not optimise all aspects of basic management, then they will not be considered for omalizumab. There must also be agreed assessment protocols, and criteria for continuing therapy, and all aspects of the process should regularly be audited. By this means, omalizumab can be targeted to those who actually need it, in whom real cost-effectiveness, the cri-de-couer of NICE, is likely. This matter is urgent; there are many more biologicals coming on line, including anti-IL-5, ${ }^{11} 12$ anti-IL-13, ${ }^{13}$ and unless we have protocols such as these in place, the whole dreary saga of omalizumab will be repeated ad nauseam. Third, we have to have better criteria for defining success of a therapy that is primarily being given to reduce the risk of attacks. Our current practice of assessing a symptom and/or lung function response at 4 months is flawed as it presupposes that omalizumab has an effect on these measures and that this effect is associated with risk reduction. It is also not easy to get an objective response to the question: how are you getting on with this therapy that costs up to $£ 25000$ per year? The major impact of treatment is improved control of eosinophilic airway inflammation. ${ }^{14}$ Might this be a better marker of response and likely risk reduction?

NICE's current proposals should actually be welcomed if they serve as a shot across the bows to professionals and the industry and if they are prepared to open constructive and joined-up discussions with professionals and the industry to ensure that current and future expensive and potentially toxic medications are used appropriately. Will we all rise to this challenge? Or will there instead be the usual sterile and acrimonious entrenched debate, as all sides vigorously defend the totally indefensible.

\section{Competing interests None.}

Provenance and peer review Not commissioned; internally peer reviewed.

To cite Bush A, Pavord ID. Thorax 2013, 68, 5-6.

Accepted 5 November 2012

Thorax 2013;68:5-6.

doi:10.1136/thoraxjnl-2012-202969

\section{REFERENCES}

1 Bush A, Saglani S. Management of severe asthma in children. Lancet 2010;376:814-25.

2 Bracken $M$, Fleming L, Hall P, et al. The importance of nurse-led home visits in the assessment of children with problematic asthma. Arch Dis Child 2009;94: 780-4.

3 American Thoracic Society. Proceedings of the ATS workshop on refractory asthma: current understanding, recommendations, and unanswered questions. Am J Respir Crit Care Med 2000;162:2341-51.

4 Bossley CJ, Fleming L, Gupta A, et al. Pediatric severe asthma is characterized by eosinophilia and remodeling without $\mathrm{T}(\mathrm{H}) 2$ cytokines. J Allergy Clin Immunol 2012;129:974-82.

5 Heaney LG, Brightling CE, Menzies-Gow A, et al. Refractory asthma in the UK: cross-sectional findings from a UK multicentre registry. Thorax 2010;65:787-94.

6 Heaney LG, Horne R. Non-adherence in difficult asthma: time to take it seriously. Thorax 2011;67: 268-70.

7 Bush A, Lenney W, Spencer D, et al. Not NICE: a better way forward? Arch Dis Child 2011;96:907-8

8 Garcia G, Magnan A, Girodet PO, et al. A proof-of-concept randomized-controlled trial of omalizumab in patients with severe difficult to control nonatopic asthma (abstract). Eur Respir J 2012;40:856s.

9 Pavord ID, Bush A. Anti-IgE for asthma in inner-city children. N Engl J Med 2011;364: 2556-7.

10 Bel EH, Sousa A, Fleming L, et al. Diagnosis and definition of severe refractory asthma: an international consensus statement from the Innovative Medicine Initiative (IMI). Thorax 2011;66:910-17.

11 Pavord ID, Korn S, Howarth P, et al. Mepolizumab for severe eosinophilic asthma (DREAM): a multicentre, double-blind, placebo-controlled trial. Lancet 2012;380:651-9.

12 Haldar P, Brightling CE, Hargadon B, et al. Mepolizumab and exacerbations of refractory eosinophilic asthma. N Engl J Med 2009:360:973-84.

13 Corren J, Lemanske RF, Hanania NA, et al. Lebrikizumab treatment in adults with asthma. N Engl J Med 2011;365:1088-98.

14 Djukanovic R, Wilson SJ, Kraft M, et al. Effects of treatment with anti-immunoglobulin $\mathrm{E}$ antibody omalizumab on airway inflammation in allergic asthma. Am J Respir Crit Care Med 2004;170:583-93. 


\section{Corrections}

Bush A, Pavord ID. Hot off the breath: Omalizumab: NICE to USE you, to LOSE you NICE. Thorax 2013;68:7-8. doi:10.1136/thoraxjnl-2012-202969. This article's citation information in the pdf should read: To cite Bush A, Pavord ID. Thorax 2013;68:7-8. doi:10.1136/ thoraxjnl-2012-202969

Thorax 2013;68:162. doi:10.1136/thoraxjnl-2012-202969corr1 